\title{
The Combination of Three Techniques for Breast Reduction: A Series of Ten Consecutive Cases
}

\author{
Alessandro Borgognone \\ Operative Unit of Plastic and Reconstructive Surgery, C.T.O. Hospital, Rome, Italy \\ Email: borgognone@gmail.com \\ Received 15 May 2014; revised 12 June 2014; accepted 9 July 2014 \\ Copyright (C) 2014 by author and Scientific Research Publishing Inc. \\ This work is licensed under the Creative Commons Attribution International License (CC BY). \\ http://creativecommons.org/licenses/by/4.0/

(c) (i) Open Access

\begin{abstract}
There is continuing controversy regarding the most effective and safest technique for breast reduction surgery. This case series describes our experience with a breast reduction approach that combines three techniques aimed at addressing three different aspects of breast reduction: skin reduction, shaping, and nipple areolar complex shaping. We assessed the perioperative course and postoperative outcomes (for a mean of 19 months) of 10 consecutive women who underwent breast reduction surgery involving a combination of three techniques: "inverted T" skin reduction, modified Hall-Findley supero-medial pedicle for glandular reduction, and inferior de-epithelialized flap (modified "Foustanos" flap) for molding and improved shaping of the breast. The final bra cup size was $C$ or $D$ in all patients. The overall results were graded as excellent in four patients and very good in six patients. Each patient was completely satisfied with her surgery. Six patients developed venous congestion of the nipple areolar complex, which resolved within 24 - 48 hours after surgery. Two patients had uneventful delayed wound healing in the vertical scar of the inverted $T$ pattern. There was a $100 \%$ nipple areolar complex survival rate. No patient had a major adverse event, permanently altered nipple areolar complex sensitivity, or bottoming out of the lower pole. None required revision surgery. This case series confirms our expectations that the solution to questions about breast reduction methods may depend on melding different techniques into a single procedure. The combination of techniques herein described was both effective and safe. Level of Evidence: Level IV, therapeutic study.
\end{abstract}

\section{Keywords}

Breast Reduction, Skin Reduction, Gland Reduction, "Foustanos" Flap, Nipple Areolar Complex Shaping 


\section{Introduction}

As the fifth most common reconstructive procedure, breast reduction is among the most frequent operations in the western world [1]. Since the majority of patients seeking breast reduction have a bra cup size of at least DD, several questions about the technical aspects of the surgery still require a definitive answer [2]. Questions remain regarding which skin pattern incision to perform, which nipple areolar complex (NAC)-transposing pedicle to choose, and which technique is the best way to mold and maintain a conical breast shape [3]-[5]. Effectively modulating these three elements is the key to a surgical result that is successful and gratifying for both the patient and the surgeon.

We herein report our experience with 10 consecutive patients undergoing breast reduction surgery involving a combination of three techniques: an “inverted T" skin reduction pattern [6], a modified Hall-Findley superomedial pedicle for glandular reduction [7]-[9], and an inferior de-epithelialized flap (modified “Foustanos” flap) [10]-[12] for molding and improved shaping of the breast.

\section{Materials and Methods}

According to the principles outlined in the Declaration of Helsinki, breast reduction using a combination of three techniques (described below) was performed by a single senior surgeon (B. A.) in 10 consecutive patients from January 2012 to June 2012. The mean follow-up period was 19 months (range, 4 to 60 months). The patients' mean age was 39.5 years (range, 18 to 65 years) and mean body mass index was $24 \mathrm{~kg} / \mathrm{m}^{2}$ (range, 19 to 37.5 $\mathrm{kg} / \mathrm{m}^{2}$ ). No patient had hypertension, diabetes, or any other major medical disorder. Five (50\%) were former smokers, all of whom stopped smoking more than 4 weeks before surgery. Each patient had a bra cup size of DD or larger. The NAC of each patient was within $10 \mathrm{~cm}$ of the sternal notch (Figure 1). Six patients (60\%) over 40 years old underwent mammography preoperatively.
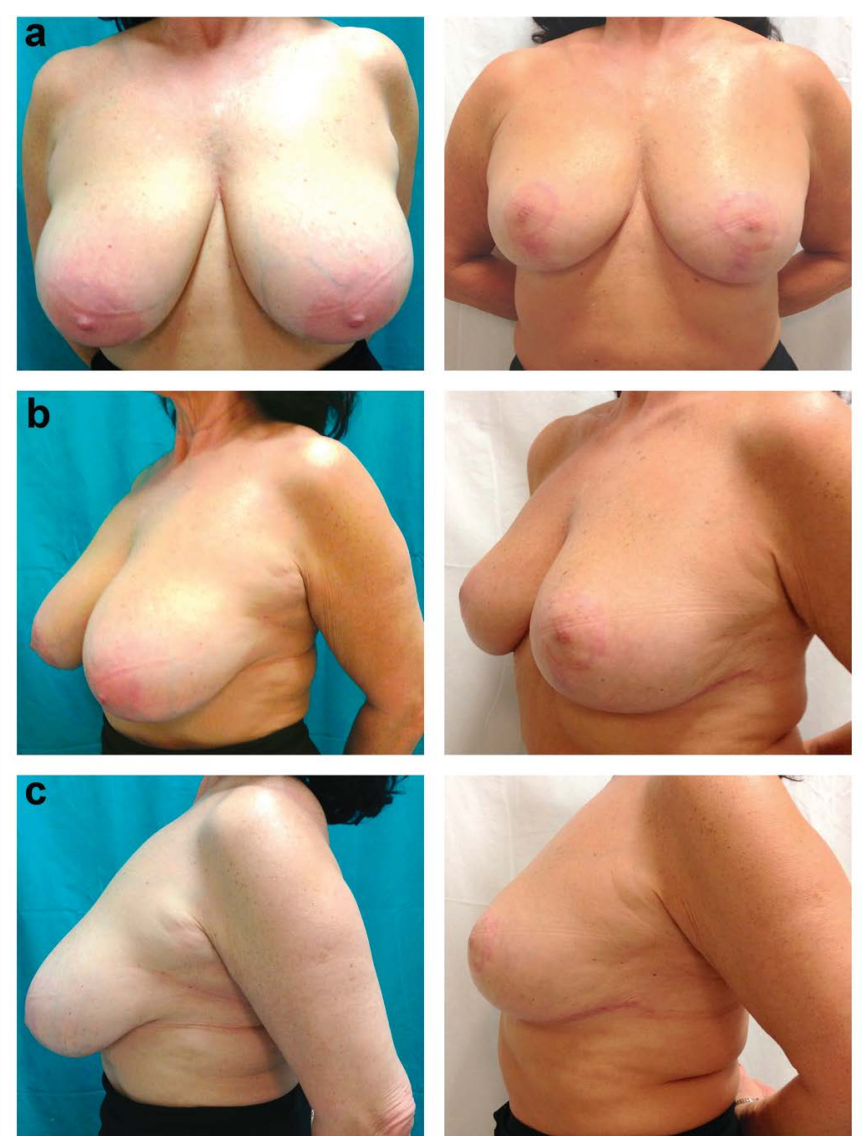

Figure 1. (a) anterior; (b) oblique; (c) lateral views of a patient preoperatively (left column) and postoperatively (right column). 
Each patient received 2 g Ceftriaxone [Rocefin; Roche Pharnaceutical, Milan, Italy] intravenously, 1 hour before surgery. The mean length of surgery was 240 minutes (range, 210 - 285 minutes). The mean quantity of breast tissue resected was $355 \mathrm{~g}$ (range, 210 - $455 \mathrm{~g}$ ) on the left and $370 \mathrm{~g}$ (range, 205 - $470 \mathrm{~g}$ ) on the right. All resected tissue was sent to the pathology laboratory for examination. A closed Redon suction drain was placed in each breast intraoperatively and subsequently removed at a mean of 4 days postoperatively (range, 3 to 9 days), when drainage was below $30 \mathrm{~mL} /$ day. Every patient received a course of postoperative antibiotics, including oral cephalexin and either Ceftriaxone [Rocefin; Roche Pharnaceutical, Milan, Italy] or Ciproxin [Ciproxin; Bayer, Whippany, NJ, USA], until the drains were removed. All patients were discharged to home on the first postoperative day. They underwent follow-up examinations on a weekly basis for 4 consecutive weeks after surgery, followed by repeat examinations at 6 and 12 months postoperatively.

Each patient underwent breast skin reduction according to the "inverted T" pattern technique. After the Biesenberger maneuver with respect to the breast meridian was performed, the gland pillars were $6-7 \mathrm{~cm}$ long (measured from the inframammary fold to the areolar border) and the keyhole was $6 \mathrm{~cm}$ wide by $4 \mathrm{~cm}$ long. The new areola had a diameter of $4-5 \mathrm{~cm}$. The gland size was reduced, sparing a $7 \mathrm{~cm}$ wide inferior de-epithelialized flap, which was fully disengaged from the inferior margin of the horizontal inframammary incision. This inferior flap was at least $2 \mathrm{~cm}$ thick. The deepening incisions into the gland pillars were rigorously maintained at $1 \mathrm{~cm}$ from the skin, leaving at least $1 \mathrm{~cm}$ of de-epithelialized dermis.

The NAC was transposed to the keyhole using a supero-medial Hall-Findley pedicle (Figure 2), modified by a wider medial undermining above the pectoral fascia, to provide space for the inferior disengaged flap. The latter was secured to the clavi-pectoral fascia and subjacent major pectoralis muscle with three superior stitches using nonabsorbable Maxilene 0 suture [Ergon Sutramed, Rome, Italy]. We preferred to keep the NAC transposing pedicle thickness at $15 \mathrm{~mm}$ and to indent it at the medial-proximal side, to facilitate its final rotation and insertion.
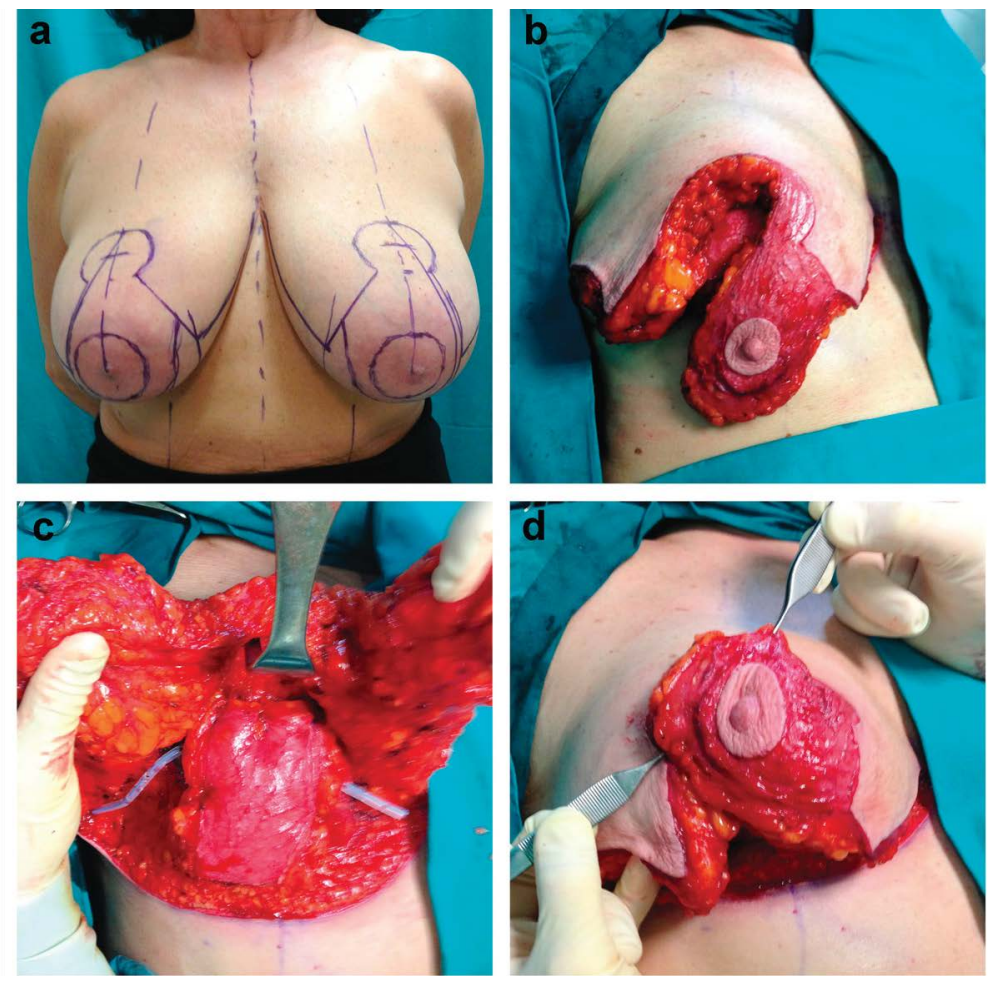

Figure 2. Photographs immediately before surgery and intraoperatively of the same patient shown in Figure 1. (a) The left upper photograph depicts the pre-incision "inverted T" pattern. The intraoperative views represent the following: (b) right upper view, Hall-Findley pedicle incised; (c) left lower view, "Foustanos" inferior flap with the right and left gland pillars splayed; and (d) right lower view, nipple-areola complex rotated. 
Poliglecaprone 3/0 sutures [Monocryl, Ethicon Johnson \& Johnson, Somerville, NJ, USA] were used for NAC insetting at the keyhole site and for approximation of the glandular pillars. Intracuticular Poliglecaprone $4 / 0$ sutures [Monocryl, Ethicon Johnson \& Johnson, Somerville, NJ, USA] were used for skin closure.

\section{Results}

Each patient underwent regular follow-up. The final bra cup size ranged between C and D. The efficacy of the surgery was evaluated by an independent plastic surgeon and trained nurse, based on breast symmetry and overall aesthetic appearance, with particular emphasis on the degree of conization and fullness of the upper pole of the breast. The results were graded on a 4-point scale (excellent, very good, good, or poor) as excellent for four patients (40\%) and very good for six patients (60\%). Each patient was completely satisfied with the surgical results and indicated that she would recommend the surgery to other possible candidates.

Six patients (60\%) developed venous congestion of the NAC, which resolved in the first 24 - 48 hours after surgery. Two patients (20\%) had uneventful delayed wound healing in the vertical scar of the inverted T pattern. No patient had a major adverse event or complication, such as a hematoma, seroma, infection, or partial or full NAC necrosis. There was a $100 \%$ survival rate of the NAC. No patient had permanently altered NAC sensitivity or bottoming out of the lower pole. No patient required revision surgery.

\section{Discussion}

The continuing controversy regarding the most effective and safest technique for breast reduction has led to many discussions and the development of many different approaches among plastic surgeons in the last few decades [4] [10] [12] [13]. The absence of definitive conclusions underscores the lack of consensus regarding a single superior approach to breast reduction.

This case series describes our experience (albeit limited) with the combined use of three previously reported techniques [12]-[14] aimed at three different aspects of breast reduction: skin reduction, shaping, and NACtransposing flap. Skin reduction using the classic "inverted T" approach [6] was ideal for our group of patients, as it closely followed the shape molded by the mobilized deep flap. Furthermore, we left $1 \mathrm{~cm}$ of de-epithelialized skin along the cut skin edge of the entire inverted $\mathrm{T}$ pattern, which limited the risk of skin dehiscence due to moderate suture stretch after compression of the "Ribeiro-Foustanos" inferior flap from behind.

In addition to carrying the NAC to the new keyhole, mobilization of the gland structures is integral for generating the ideal conical shape of the new breast. For "conization" of the gland, we did not rely solely upon the supero-medial pedicle, as we do not think that it is possible to maintain a durable conical shape with this pedicle alone. Instead, we undermined a wide pocket on the pectoral fascia, preserving the medial border of the gland and its blood supply for the pedicle [15]; this is the pocket into which the associated inferior flap was inset [16]. A supero-medial pedicle was used to transpose the NAC to the new keyhole, as it is reliably associated with NAC survival [15]. This allowed us to excise a full crescent of gland at the medial and uppermost side of the pedicle to facilitate insetting the NAC at the new keyhole.

For the inferior-based de-epithelialized flap, we chose a $7 \mathrm{~cm}$ wide flap centered on the breast meridian, which was completely disengaged and untethered from the inframammary fold. Its vascular supply, arising from the fourth intercostal artery, was always resilient enough to allow the flap to be moved upward to counteract the flatness of the breast usually seen after a reduction, even when the Hall-Findley technique is used.

Our herein described approach to breast reduction was associated with a high frequency of venous stasis of the NAC, although this fully resolved within 48 hours in all patients. The transient venous stasis may have been caused by the sudden increase in pressure applied by the inferior flap on the undersurface of the supero-medial pedicle. Recovery of the NAC circulation may be easier and faster if a finger is used to "smooth" and "comb" any unevenness of the deep surface of the pedicle after juxtaposing the pedicle and inferior flap, but before placing the vertical sutures of the glandular pillars.

\section{Conclusions}

The experience collected with this small series of patients confirms our expectations that the solution to questions about breast reduction may depend on the melding of different procedures into a single one, instead of relying on merely a single technique. The use of a combination of techniques may be applicable to other types of 
surgery as well.

This small series does not pretend to be a state of the art conclusion about the best method possible to approach breast reduction. This is either because of the small number of patients involved or because of the lack of any statistical issue carried out with comparable cohorts of patients assigned to each procedure that in this study are mixed up.

Notwithstanding it could warrant future and more articulated trials.

\section{Acknowledgements}

The authors declare that they have no conflict of interest.

\section{Commercial Interests}

None.

\section{Ethical Approval}

All procedures performed in studies involving human participants were in accordance with the ethical standards of the institutional and/or national research committee and with the 1964 Helsinki declaration and its later amendments or comparable ethical standards.

\section{References}

[1] Clark, C., Whang, S. and Paige, K.T. (2009) Incidence of Precancerous Lesions in Breast Reduction Tissue: A Pathologic Review of 562 Consecutive Patients. Plastic and Reconstructive Surgery, 124, 1033-1039. http://dx.doi.org/10.1097/PRS.0b013e3181b45801

[2] Kerrigan, C.L. and Slezak, S.S. (2013) Evidence-Based Medicine: Reduction Mammoplasty. Plastic and Reconstructive Surgery, 132, 1670-1683. http://dx.doi.org/10.1097/PRS.0b013e3182a807ec

[3] Abramson, D.L., Pap, S., Shifteh, S. and Glasberg, S.B. (2005) Improving Long-Term Breast Shape with the Medial Pedicle Wise Pattern Breast Reduction. Plastic and Reconstructive Surgery, 115, 1937-1943. http://dx.doi.org/10.1097/01.PRS.0000165085.23537.A7

[4] Graf, R. and Biggs, T.M. (2002) In Search of Better Shape in Mastopexy and Reduction Mammoplasty. Plastic and Reconstructive Surgery, 110, 309-317. http://dx.doi.org/10.1097/00006534-200207000-00053

[5] Spear, S.L. and Mijidian, A. (1998) Reduction Mammaplasty and Mastopexy: General Considerations. In: Spear, S.L., Ed., Surgery of the Breast: Principles and Art, Lippincott-Raven, Philadelphia, 673-684.

[6] Wise, J. and Robert, J. (1956) A Preliminary Report on a Method of Planning the Mammaplasty. Plastic and Reconstructive Surgery, 17, 367-375. http://dx.doi.org/10.1097/00006534-195605000-00004

[7] Finger, R.E., Vasquez, B., Drew, G.S. and Given, K.S. (1989) Superomedial Pedicle Technique of Reduction Mammaplasty. Plastic and Reconstructive Surgery, 83, 471. http://dx.doi.org/10.1097/00006534-198903000-00012

[8] Hall-Findlay, E. (2002) Vertical Breast Reduction with a Medially-Based Pedicle. Aesthetic Plastic Surgery, $22,185$. http://dx.doi.org/10.1067/maj.2002.123052

[9] Nahabedian, M.Y., McGibbon, B.M. and Manson, P.N. (2000) Medial Pedicle Reduction Mammaplasty for Severe Mammary Hypertrophy. Plastic and Reconstructive Surgery, 105, 896. http://dx.doi.org/10.1097/00006534-200003000-00011

[10] Ribeiro, L. (1975) A New Technique for Reduction Mammaplasty. Plastic and Reconstructive Surgery, 55, 330-334. http://dx.doi.org/10.1097/00006534-197555030-00010

[11] Foustanos, A. and Zavrides, H. (2007) A Double-Flap Technique: An Alternative Mastopexy Approach. Plastic and Reconstructive Surgery, 120, 55-60. http://dx.doi.org/10.1097/01.prs.0000263320.57385.a2

[12] Bonomi, S., Salval, A., Settembrini, F., Gregorelli, C., Musumarra, G. and Rapisarda, V. (2012) Inferiorly Based Parenchymal Flap Mammaplasty: A Safe, Reliable, and Versatile Technique for Breast Reduction and Mastopexy. Plastic and Reconstructive Surgery, 130, 116e-125e. http://dx.doi.org/10.1097/PRS.0b013e318254b552

[13] Hall-Findlay, E.J. (2012) Discussion: Inferiorly Based Parenchymal Flap Mammaplasty: A Safe, Reliable, and Versatile Technique for Breast Reduction and Mastopexy. Plastic and Reconstructive Surgery, 130, 126e-127e. http://dx.doi.org/10.1097/PRS.0b013e318254b486

[14] Bonomi, S., Settembrini, F., Salval, A., Musumarra, G. and Gregorelli, C. (2012) How to Improve Shape and Projec- 
tion in Mastopexy. Plastic and Reconstructive Surgery, 29, 758e-759e. http://dx.doi.org/10.1097/PRS.0b013e318245e865

[15] Hall-Findlay, E.J. (2013) Discussion: A Matched Cohort Study of Superomedial Pedicle Vertical Scar Breast Reduction (100 Breasts) and Traditional Inferior Pedicle Wise-Pattern Reduction (100 Breasts): An Outcomes Study over 3 Years. Plastic and Reconstructive Surgery, 132, 1077-1079. http://dx.doi.org/10.1097/PRS.0b013e3182a48bb4

[16] Lockwood, T. (1999) Reduction Mammaplasty and Mastopexy with Superficial Fascial System Suspension. Plastic and Reconstructive Surgery, 103, 1411. http://dx.doi.org/10.1097/00006534-199904020-00009 
Scientific Research Publishing (SCIRP) is one of the largest Open Access journal publishers. It is currently publishing more than 200 open access, online, peer-reviewed journals covering a wide range of academic disciplines. SCIRP serves the worldwide academic communities and contributes to the progress and application of science with its publication.

Other selected journals from SCIRP are listed as below. Submit your manuscript to us via either submit@scirp.org or Online Submission Portal.
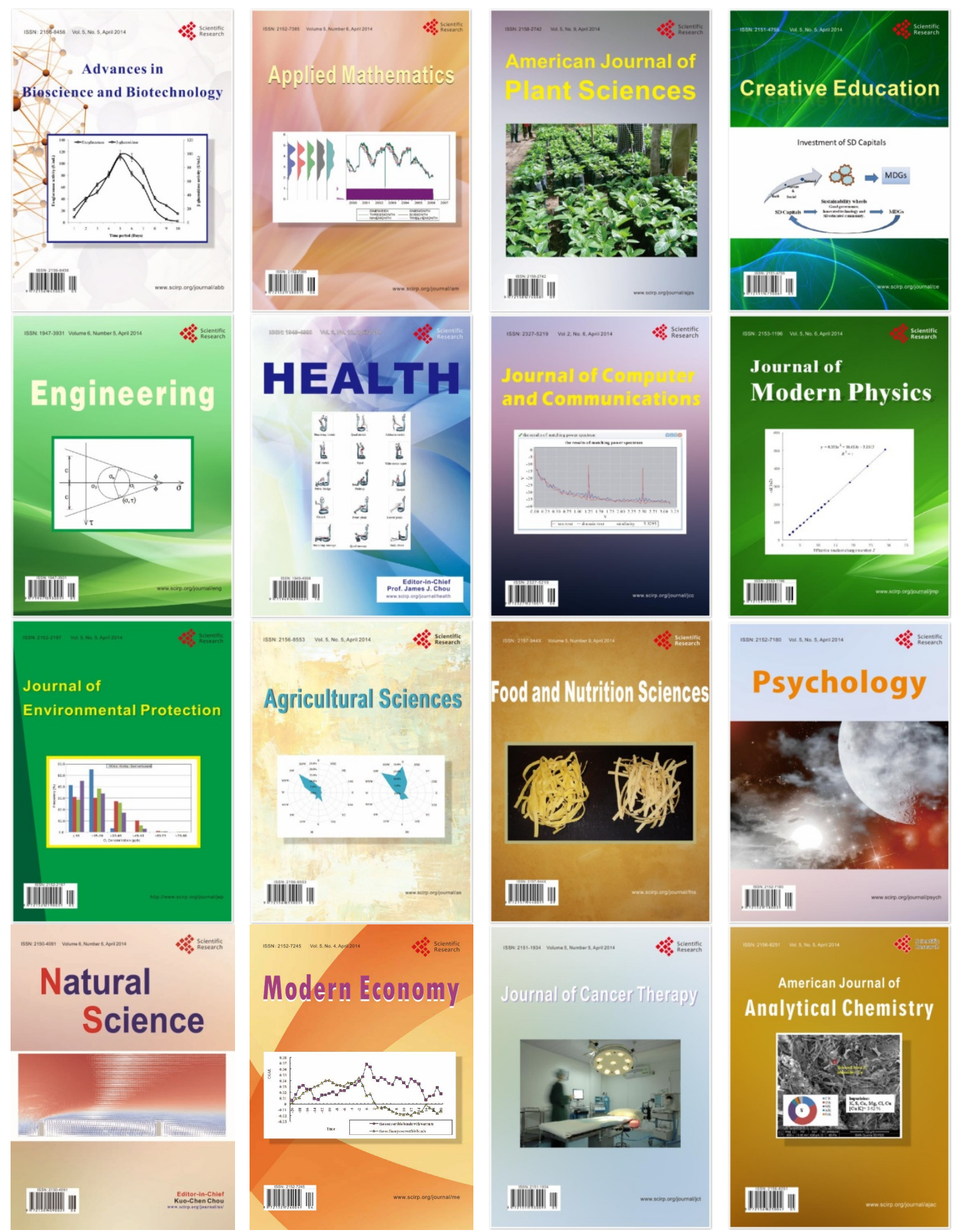